Original Article

\title{
The influence of accuracy constraints on EMG and kinetic variables during gait initiation
}

\author{
Hyeong-Dong Kim, PhD, $\mathrm{PT}^{1)^{*}}$, Denis Brunt, EdD, PT ${ }^{2)}$, Hyun Dong Je, PhD ${ }^{3)}$ \\ 1) Department of Physical Therapy, College of Health Science, Korea University: 145 Anam-ro, Hana \\ Science Building B, Seongbuk-gu, Seoul 136-701, Republic of Korea \\ 2) Department of Physical Therapy, Nicole Wertheim College of Nursing and Health Sciences, Florida \\ International University, USA \\ 3) Department of Pharmacology, College of Pharmacy, Catholic University of Daegu, Republic of \\ Korea
}

\begin{abstract}
Purpose] This study investigated the effects of accuracy constraints (targets) placed on the steppinglimb heel-strike (HS) on the electromyogram (EMG) and ground reaction forces (GRFs) during gait initiation. [Subjects and Methods] Twenty healthy subjects (29.2 \pm 2.9 years) were asked to begin walking or stepping over a $10-\mathrm{cm}$-high obstacle at a fast speed. A 3-cm-diameter target was placed on the ground to dictate the position and accuracy of the stepping-limb HS. [Results] The results showed that the initiation velocity increase in the no-target conditions was due to modulation of the stance- and stepping-limb GRFs and a corresponding increase in the tibialis anterior (TA) activities of both limbs before stepping-limb toe-off. This was achieved by significantly increasing the stepping- and stance-limb TAEMG1 (determined between the onset of movement and time to peak anteroposterior (A-P) GRF of the stepping- and stance- limb) for the no-target conditions. It seems, therefore, that TAEMG1 and the slope to stepping-limb peak A-P GRF contributed to the intended velocity of initiation. [Conclusion] These data indicate that gait initiation and/or stepping over an obstacle may prove to be tasks by which motor control can be measured. The present study provides insight into the working mechanisms of the stepping and stance limbs and shows a clear need to further investigate whether the intact or affected limb should be used to initiate gait during rehabilitation and prosthetic training.

Key words: Electromyogram, Gait initiation, Ground reaction forces
\end{abstract}

(This article was submitted Oct. 6, 2014, and was accepted Nov. 28, 2014)

\section{INTRODUCTION}

Gait initiation (GI) is the transition from an upright stance to a steady-state gait. It is a movement that can be completed in the absence of plantar surface feedback ${ }^{1)}$ and is presumably preprogrammed ${ }^{2}$. In quiet stance, the inhibition of the soleus (SOL) and the activation of the tibialis anterior (TA) result in a dorsiflexion torque, forward propulsive force, and a backward movement of the center of pressure $(\mathrm{COP})^{3-5)}$. The COP and center of mass (COM) become decoupled, and a fall forward is initiated. In addition, the stepping-limb hip abductors create movement of the COP toward that limb ${ }^{6}$. Thus, muscle activity at the ankle and hip propels the COM forward and toward the intended stance limb to allow stepping-limb toe-off (TO) and the first step ${ }^{7-9}$ ).

Several papers have focused on the intended velocity of GI. Of interest has been the modulation of ground reaction

*Corresponding author. Hyeong-Dong Kim (E-mail: hdkimx0286@yahoo.com)

C2015 The Society of Physical Therapy Science. Published by IPEC Inc. This is an open-access article distributed under the terms of the Creative Commons Attribution Non-Commercial No Derivatives (by-ncnd) License $<$ http://creativecommons.org/licenses/by-nc-nd/3.0/>. forces (GRFs) and muscle activity before stepping-limb TO with changes in intended velocity. As would be expected, the posterior displacement of the COP and the propulsive force have been shown to increase, and the time to this peak force decrease, with an increase in the intended velocity of $\mathrm{GI}^{4,10-13)}$. The duration of both stepping and stance TA activities increase with the velocity of $\mathrm{GI}^{4,5,14)}$. Significant correlations between kinetic events, time to stepping-limb TO, amplitude and duration of TA, and intended velocity of GI have been reported ${ }^{5)}$. Similar patterns of modulation seem to occur when stepping to a new height ${ }^{15}$ ) or over an obstacle ${ }^{7,16-21)}$

Previous studies have described the velocity-dependent characteristics of GI. However, no single study has reported electromyogram (EMG) and GRF data of both the stance and stepping limbs and their relation to the intended velocity of GI. One reason for this has been the use of a single force plate $^{12,13,22-27)}$ and the other is that EMG activity was not measured $^{1,28-37)}$ in many studies.

Information on both the stepping and stance limbs is valuable in a rehabilitation setting where accurate patient education and documentation of change is required. This information has uses when an asymmetrical lower-limb function is caused by injury or disease, and the patient not only has to generate the required forces, but also strategize as to 
which limb should be the stepping limb. For example, time to stepping-limb TO has been shown to be slower in stroke patients when the hemiplegic limb is the stance limb ${ }^{28}$, yet others have reported the initiation velocity to be greater if the hemiplegic limb is the stance $\operatorname{limb} b^{30,35)}$. Tokuno and Eng $^{35)}$ reported decreased anteroposterior (A-P) forces from the hemiplegic limb, regardless of whether it was leading or trailing, and questioned whether the hemiplegic limb should be the stepping or trailing stance limb. Those with a lowerlimb amputation tend to initiate gait with the prosthetic limb. The force generated by this limb is low, and a rescaling of the force of the sound limb is necessary for an adequate first step length ${ }^{36)}$.

Information on the interaction of the stance and stepping limbs during GI could help guide rehabilitation decisions. Moreover, how this interaction changes with the velocity of GI is also important, given that an increase in gait velocity is a positive indicator of recovery ${ }^{38-41)}$. If the velocity and strategy employed to initiate gait is important in rehabilitation, the collection of more comprehensive data from healthy subjects is required. The purpose of this study was, therefore, to investigate the effects of accuracy constraints (targets) placed on the stepping-limb heel-strike (HS) on muscle activities and GRF during GI. We hypothesized that the velocity of GI and stepping over an obstacle would decrease when accuracy constraints were placed on the stepping-limb HS, and our results show this decrease was the result of the modulation of GRFs and muscle activities of both the stance and stepping limbs before stepping-limb TO.

\section{SUBJECTS AND METHODS}

The study sample consisted of twenty healthy participants (ten males and ten females; mean age, $29.2 \pm 2.9$ years; range, 24-34 years) with no known neurological or orthopedic deficits. The study was approved by the university institutional review board, and all participants signed an informed consent form. The study participants' characteristics are summarized in Table 1.

Surface electrodes were applied to the center of the muscle bellies of the TA and SOL of the stance and stepping limbs. Each recording electrode consisted of two silver-silver chloride 1-cm-diameter electrodes, embedded in an epoxy-mounted preamplifier system $(\times 35)$, and their centers were spaced $2 \mathrm{~cm}$ apart. A reference electrode was attached to the medial aspect of the tibia. The EMG signals were high-pass filtered $(20 \mathrm{~Hz}-4 \mathrm{KHz})$ using a zero-lag filter (Therapeutics Unlimited, Iowa City, IA, USA) to remove movement artifacts and full-wave rectified online. The final amplification was $10 \mathrm{~K}$. The collection and processing of EMG data followed SENIAMS recommendations ${ }^{42)}$.

Two force platforms (Advanced Mechanical Technology, Inc., Newton, MA, USA), embedded in a level walkway (5 m length, $1.22 \mathrm{~m}$ width), measured the GRFs of the stance and stepping limbs. The GRFs (kinetic data) were collected at $1,000 \mathrm{~Hz}$ and later filtered with a 4th order, Butterworth, zero lag filter, with a cutoff frequency of $50 \mathrm{~Hz}$. Foot switches (B \& L Engineering, Los Angeles, CA, USA) were placed in the shoes to measure the HS of the stepping limb. The EMG and foot switch signals were synchronized with the
Table 1. Subject characteristics

\begin{tabular}{lcclc}
\hline Gender & Number & Age (years) & Height $(\mathrm{cm})$ & Weight $(\mathrm{kg})$ \\
\hline Male & 10 & $30.2(2.78)$ & $174.8(5)$ & $71.2(3.79)$ \\
Female & 10 & $28(2.69)$ & $164.6(5.24)$ & $53.4(3.09)$ \\
Total & 20 & $29.2(2.9)$ & $169.9(7.3)$ & $62.8(9.72)$ \\
\hline
\end{tabular}

kinetic data to simultaneously start both the EMG and foot switch data capture. Both the EMG and the force platform data were recorded simultaneously on a personal computer at a sampling rate of $1,000 \mathrm{~Hz}$ for $4 \mathrm{~s}$ (BIOPAC Systems, Goleta, CA, USA). The test conditions included the use of an obstacle (10 cm height, $10 \mathrm{~cm}$ depth, and $140 \mathrm{~cm}$ width) made of wood.

For each trial, participants stood in a predetermined position with each foot on a force platform. Participants were asked to begin walking or stepping over the obstacle, at a fast speed, with the limb they naturally preferred to initiate gait with, after receiving the verbal cue "Go," and to continue to walk a minimum of three steps. Before the experimental trials, the average position of the stepping HS was determined for each subject using a video analysis. For half of the experimental trials, a 3-cm-diameter target was placed on the ground to dictate the position and accuracy of the stepping-limb HS. All participants performed two practice trials to familiarize themselves with the experimental procedure. Participants completed 10 trials under each of the following four conditions: GI, GI to the target, stepping over the obstacle, and stepping over the obstacle to the target. The order of the conditions was randomized. The few trials in which the subject missed the target were repeated. All participants were required to wear flat-soled shoes normally used for everyday walking or sports activities.

Two-way analysis of variance (initiation condition $\times$ accuracy) for repeated measures was performed to determine the main and interaction effects of A-P GRFs, muscle response, and temporal events. Post hoc analysis using Turkey's HSD was used to determine the between-group mean differences if the analysis of variance found a significant main effect or interaction of initiation condition $\times$ accuracy. A p-value of $<$ 0.05 was considered statistically significant.

The independent variables were initiation condition (GI and stepping over an obstacle) and accuracy (target, no target). The dependent measures included EMG amplitude, slopes and peak of the propulsive GRF, and timing events of GI. The amplitude of stance- and stepping-limb TA EMG was determined between the onset of movement and time to peak A-P GRF of the stepping limb (TAEMG1), and between time to stepping-limb peak A-P GRF and stepping-limb TO (TAEMG2). The amplitude and duration of stepping-limb SOL activity were also calculated. The onset and offset of SOL activity was visually determined with an interactive cursor of 1-ms resolution. GRF data were normalized as percent body weight $(\% \mathrm{BW})$. Time to stepping-limb TO, stepping-limb HS, stance-limb heel-off, and stance limb TO were also determined. Timing data were referenced from the onset of movement, which was defined as the first detectable onset of force platform activity. An investigator blinded 
Table 2. Means (SD) of temporal events (ms)

\begin{tabular}{|c|c|c|c|c|}
\hline \multirow[t]{2}{*}{ Dependent variables } & \multicolumn{2}{|c|}{ Gait Initiation } & \multicolumn{2}{|c|}{ Stepping } \\
\hline & no target & target & no target & target \\
\hline Stepping limb peak $\mathrm{Fx}^{\#}$ & $340(49)^{\S}$ & $423(42)^{\S \Omega}$ & $329(47)^{\uparrow}$ & $368(73)^{\Phi \Omega}$ \\
\hline Stepping limb toe-off ${ }^{*+}$ & $511(76)^{\S \Gamma}$ & $613(81)^{\S \Omega}$ & $475(69)^{9 \Gamma}$ & $548(91)^{q_{\Omega}}$ \\
\hline Stepping limb heel-strike ${ }^{*+}$ & $890(74)^{\S \Gamma}$ & $1008(86)^{\S \Omega}$ & $968(71)^{9 \Gamma}$ & $1071(108)^{q_{\Omega}}$ \\
\hline Stance limb toe-off ${ }^{*+}$ & $1024(76)^{\S \Gamma}$ & $1219(156)^{\S \Omega}$ & $1093(85)^{9 \Gamma}$ & $1257(153)^{\llbracket \Omega}$ \\
\hline
\end{tabular}

Values represent mean \pm standard deviation (SD).

*Significant main effect of target $(p<0.01$ or $p<0.05)$.

${ }^{+}$Significant main effect of initiation condition $(\mathrm{p}<0.01$ or $\mathrm{p}<0.05)$.

\#Significant interaction $(\mathrm{p}<0.05)$.

${ }_{\S \Omega \uparrow}$ Significant difference between conditions $(\mathrm{p}<0.01$ or $\mathrm{p}<0.05)$.

Table 3. Means (SE) of EMG dependent variables (ms.v)

\begin{tabular}{|c|c|c|c|c|}
\hline \multirow[t]{2}{*}{ Dependent variables } & \multicolumn{2}{|c|}{ Gait Initiation } & \multicolumn{2}{|c|}{ Stepping } \\
\hline & no target & target & no target & target \\
\hline Stance limb TAEMG1 & $340(49)^{\dagger *}$ & $423(42)^{\ddagger}$ & $329(47)^{\dagger \S}$ & $368(73)^{\S}$ \\
\hline Stance limb TAEMG2* & $511(76)^{\Pi}$ & $613(81)^{\Pi}$ & $475(69)^{9}$ & $548(91)^{9}$ \\
\hline Stepping limb TAEMG1* & $890(74) \Pi$ & $1008(86) \Pi$ & $968(71)^{\uparrow}$ & $1071(108)^{9}$ \\
\hline Stepping limb TAEMG2 & $1024(76)$ & $1219(156)$ & $1093(85)$ & $1257(153)$ \\
\hline 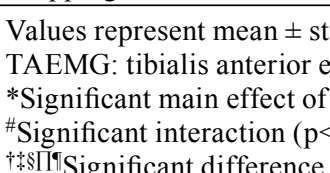 & $\begin{array}{l}\text { deviation }(\mathrm{S} \\
\text { nyogram. } \\
(\mathrm{p}<0.01 \text { or } \mathrm{p}\end{array}$ & $x_{0}$ & & \\
\hline
\end{tabular}

to the experimental trials performed all determinations of muscle activity timing and change in GRF. SPSS $14.0 \mathrm{KO}$ (SPSS Korea Inc., Seoul, Korea) was used for statistical analyses.

\section{RESULTS}

The temporal events are shown in Table 2. Although there was an interaction $(F(1,8)=6.47, \mathrm{p}<0.05)$ of the time to stepping-limb peak A-P GRF (the target condition for stepping over an obstacle was greater than that for GI), the mean times to peak A-P GRF in the target conditions were significantly greater than in the no-target conditions. The time to stepping-limb TO showed significant main effects of both the initiation and target conditions $(F(1,8)=10.87$, $\mathrm{p}<0.05$ and $F(1,8)=19.29, \mathrm{p}<0.01$, respectively). Time to stepping-limb TO was longer in stepping to the target but shorter in the obstacle condition. The times to stepping-limb HS and stance-limb TO showed main effects of the initiation and target conditions $(F(1,7)=7.83$ to $18.24, \mathrm{p}<0.01$ to $\mathrm{p}$ $<0.05)$. The times increased in both the target and stepping conditions. These data clearly show that the target decreased the GI velocity.

The amplitude of the TA EMG was determined from both the onset of force platform activity to stepping-limb peak A-P GRF (TAEMG1), and from stepping-limb peak A-P GRF to TO of the stepping limb (TAEMG2). There was a significant main effect of target on the stepping-limb TAEMG1 $(F(1$, $8)=7.75, p<0.05)$ which showed decreased amplitudes in the target conditions (Table 3). However, there was no significant effect on the TAEMG2 of the stepping limb.

Stance TAEMG1 showed a significant interaction $(F(1$, $8)=12.12, p<0.05)($ Table 3$)$. Stance TAEMG1 was greater in GI than in the stepping over the obstacle with no target, but showed no difference between the target conditions. Stance TAEMG2 was significantly greater in the no-target conditions than in the target conditions $(F(1,8)=13.31$, $\mathrm{p}<0.01$ ) (Table 3). The mean data show that except for TAEMG2 of the stepping limb, the TA amplitude was clearly greater in the no-target conditions. The stepping-limb SOL EMG amplitude was similar in all the conditions; however, its duration was $24 \mathrm{~ms}$ greater in the target conditions $(F(1$, $8)=8.05, \mathrm{p}<0.05)$.

There was a significant main effect of target on both the stepping-limb peak A-P GRF $(F(1,8)=30.88, \mathrm{p}<0.001)$ and the slope to stepping-limb peak A-P GRF $(F(1,8)=18.2$, $\mathrm{p}<0.01)$. Values were greater in the no-target conditions (Table 4). There was no significant difference between the GI and stepping over the obstacle conditions for either dependent variable. Although there was a significant interaction of the stance-limb peak A-P GRF $(F(1,8)=13.64$, p < $0.01)$, there were also main effects of the stepping $(F(1,8)=$ $30.07, \mathrm{p}<0.01)$ and target $(F(1,8)=24.80, \mathrm{p}<0.01)$ conditions. Stance-limb peak A-P GRF was greater in the GI and no-target conditions (Table 4). The slope to peak A-P GRF showed a main effect of target only and the slope was greater in the no-target conditions $(F(1,8)=22.27, \mathrm{p}<0.01)$. 
1026 J. Phys. Ther. Sci. Vol. 27, No. 4, 2015

Table 4. Means (SD) of peak (\%BW) and slope $(\% \mathrm{BW} / \mathrm{s})$ force plate dependent variables

\begin{tabular}{|c|c|c|c|c|}
\hline \multirow[t]{2}{*}{ Dependent variable } & \multicolumn{2}{|c|}{ Gait Initiation } & \multicolumn{2}{|c|}{ Stepping } \\
\hline & no target & target & no target & target \\
\hline Stepping limb peak $\mathrm{Fx}^{*}$ & $39.6(6)^{\Pi}$ & $26(7.8) \Pi$ & $40.8(9.6)^{\natural}$ & $25.7(7.2)^{ף}$ \\
\hline Stepping limb slope $\mathrm{Fx}^{*}$ & $125.2(42)^{\Pi}$ & $62(22.5) \Pi$ & $120.6(26.4)^{\llbracket}$ & $75.6(32.3)^{9}$ \\
\hline Stance limb peak $F^{\#}$ & $81.8(13) \Pi \S$ & $52.6(12) \Pi$ & $66.3(15)^{\S \oplus}$ & $47.5(13)^{\uparrow}$ \\
\hline Stance limb slope $\mathrm{Fx}^{*}$ & $318.2(63) \Pi$ & $208.2(53)^{\Pi}$ & $313.1(87)^{\pi}$ & $192.5(54)^{\natural}$ \\
\hline
\end{tabular}

Values represent mean \pm standard deviation (SD).

Fx: anteroposterior ground reaction force; \%BW: percent body weight; \%BW/s: percent body weight per second.

*Significant main effect of target $(\mathrm{p}<0.01$ or $\mathrm{p}<0.05)$.

\#Significant interaction $(\mathrm{p}<0.05)$.

$\prod_{\uparrow}$ Significant difference between conditions $(\mathrm{p}<0.01$ or $\mathrm{p}<0.05$ ).

\section{DISCUSSION}

A unique relation exists between force profiles and muscle activity in different movement strategies. An increase in the degree of accuracy of a task causes a decrease in the velocity of movement ${ }^{43-45)}$. Therefore, there must be a change in strategy with an accuracy constraint, but only if the accuracy demands are sufficiently sensitive to dictate movement velocity ${ }^{46)}$. Furthermore, on the basis of previous studies of GI and stepping ${ }^{7,8)}$, it could be concluded that by manipulating the limb trajectory, for example, stepping over an obstacle as opposed to GI, forces would remain invariant. By investigating the component of GI thought to dictate the velocity of movement, better data on how forces are modulated during voluntary movement from a quiet stance could be provided.

The current study investigated both GI and stepping over an obstacle and the interaction of the stance limb with the stepping limb, when target constraints were placed on the stepping-limb HS. The results show that the initiation velocity increase in no-target conditions was due to the modulation of the stance- and stepping-limb GRFs and the corresponding increase of the TA activity in both limbs before stepping-limb TO. This was achieved by significantly increasing the stepping- and stance-limb TAEMG1 in the no-target conditions. It seems, therefore, that TAEMG1 and the slope to stepping-limb peak A-P GRF contributed to the intended velocity of initiation (GI or stepping over an obstacle).

In the present study, the accuracy constraint clearly decreased the speed of GI. Stepping-limb TO marks the first significant event, and in the no-target condition it occurred approximately $90 \mathrm{~ms}$ earlier than in the target conditions. This decrease in time was, in part, due to a $15 \%(61 \mathrm{~ms})$ decrease in time to stepping-limb peak A-P GRF of the notarget conditions. This decrease in time to peak A-P GRF was due to a $78 \%$ increase in slope to peak A-P GRF that resulted in a $55 \%$ increase in peak A-P GRF of the stepping limb. Given the relative changes in time and slope, it seems that subjects modulated the rate of increase of force and kept the time to peak force relatively constant to achieve the increase in the peak acceleration force of the stepping limb. As the TA controls the backward movement of the $\mathrm{COP}^{3,4,10,47)}$, there was a significant increase in stepping-limb TAEMG1 in the no-target conditions. The relation between the backward movement of the $\mathrm{COP}^{10,48)}$ or TA activity and gait velocity has previously been recognized. Of interest, the time from stepping-limb TO to stepping-limb HS remained invariant for both GI and stepping over the obstacle, a finding supported by the earlier data of Brenière and colleagues ${ }^{3,10,47)}$. In the present study, the mean difference between the accuracy conditions was only $23 \mathrm{~ms}$. Furthermore, there was no main effect of the amplitude of stepping-limb TAEMG2 or SOL, and it has been previously recognized that SOL creates heel rise in preparation for the first step but does not contribute toward gait velocity ${ }^{48)}$. The contribution of the stepping limb to the velocity of initiation (GI or stepping) seems, therefore, to be determined by TAEMG1 and the slope to steppinglimb peak A-P GRF ${ }^{48)}$.

For the stance limb, there was a significant target effect on both TAEMG1 and TAEMG2. In both stepping over the obstacle and GI, the amplitude of TAEMGI was far greater than that of TAEMG2, and only minimal acceleration force was generated until the slope to stance-limb A-P GRF appeared. The onset of this slope coincided with the peak A-P GRF of the stepping limb, our selected time division between TAEMG1 and TAEMG2. During this phase of GI and stepping over an obstacle, the stepping limb is loaded and the stance limb unloaded. This transition from unloading to loading occurs slightly before peak A-P GRF of the stepping limb. Given the greater amplitude of TAEMG1 of the stance limb but smaller peak force, we consider that the smaller A-P GRF is probably related to the unloading of the stance limb, and slope to stance-limb peak A-P GRF to the loading of that limb before stepping-limb TO. The slope to stance-limb peak A-P GRF was the same for GI and stepping over the obstacle, but peak A-P GRF was less when stepping over the obstacle. Peak A-P GRF coincides with stepping-limb TO, and the earlier TO for stepping (and therefore smaller peak A-P GRF) is thought to be related to the trajectory of the stepping limb ${ }^{7)}$. Because of the greater trajectory, the time to stepping-limb HS from TO was longer for stepping over the obstacle.

The slope to stance-limb peak A-P GRF increased in the no-target condition. There was an increase of approximately $50 \%$ in the no-target condition, with only a $14 \%$ difference in time to peak A-P GRF. The increase in the slope to peak A-P GRF of the stepping limb was $78 \%$. For the stance limb, these data differ from a previous report ${ }^{8)}$ that used both a 
large and a small target. However, it should be noted that the target size used in the present study was $50 \%$ smaller than the small target used in the previous study ${ }^{8}$. In an isometric plantar flexion task, the slopes to peak forces were also found to be the same once the target size had reached a critical level. That is, the targets were too large to influence movement velocity ${ }^{46)}$. The fact that an explicit instruction to increase the velocity of GI (as opposed to accuracy constraints) resulted in an increase in the slope to stance-limb peak A-P GRF supports this interpretation ${ }^{7)}$.

We acknowledge that there were some limitations of this study. Because the experiment was only conducted on a relatively small sample of healthy young adults (GI in a non-pathological setting), our findings cannot be generalized to the population with a pathological GI. Moreover, much of the pathological GI condition is asymmetrical, yet data is only presented for right foot gait initiation. Furthermore, data was only collected at a fast speed, and we used experimental manipulations such as a target and obstacle-crossing instead of asking the participants to simply initiate their gait at slow, preferred, and fast speeds.

In conclusion, this study investigated changes in EMG and GRF responses during GI at different intended velocities of initiation. The velocity of GI and stepping over an obstacle increased when no accuracy constraints were placed on the stepping-limb HS. This increase was due to the modulation of both the stance- and stepping-limb GRFs before steppinglimb TO. The time to these peak forces remained relatively constant (100-ms less in the no-target conditions). That is, the slope to the stepping- and stance-limb peak A-P GRF was modulated, whereas the time to peak A-P GRF remained relatively constant. This notion is supported by the strong correlations between the slope to stepping-limb A-P GRF and time to stepping HS $(r=0.84)$, and the more modest correlation $(r=0.64)$ of the slope to stance-limb peak A-P GRF. Furthermore, there were no differences in the slopes to either stepping- or stance-limb peak A-P GRF between GI and stepping over the obstacle. This concurs with upperextremity studies showing that the distance moved does not affect the rate of increase of force. On the basis of these data, GI and/or stepping over an obstacle may prove to be tasks which can measure motor control. This would be preferable in upper-extremity experiments, for which the subject sits and the extremity is stabilized. Voluntary movement from an upright stance may be useful for assessing changes in performance after rehabilitation.

Hemiparetic patients show an asymmetric gait pattern and prefer initiating gait with the affected leg to utilize the higher stability of the supporting limb. However, hemiparetic patients are encouraged to initiate gait with the intact limb to increase the weight-bearing ability of the affected leg. Similarly, unilateral amputees in rehabilitation training are also encouraged to lead with the intact limb when stepping up, and with their prosthetic limb when stepping down ${ }^{49)}$. However, a recent study ${ }^{30)}$ questions whether initiating the gait of hemiplegic patients with the intact limb is related to a higher risk of fall. The movement pattern of the COP and $\mathrm{COM}$ is altered in patients with hemiparetic stroke when initiating gait with the unaffected leg. This difference may be attributable to the higher incidence of falls when initiat- ing gait with the unaffected leg due to the altered movement pattern of the COP and COM. The present study provides insight into the working mechanisms of the stepping and stance limbs and shows the clear need to further investigate whether the intact or affected limb should be used to initiate gait during rehabilitation and prosthetic training.

\section{ACKNOWLEDGEMENTS}

This research was supported by a Korea University Grant (K1325021). The authors would like to thank the participants for their participation in this study and the reviewers for their insightful comments and suggestions.

\section{REFERENCES}

1) Fiolkowski $P$, Brunt $D$, Bishop $M$, et al.: Does postural instability affect the initiation of human gait? Neurosci Lett, 2002, 323: 167-170. [Medline] [CrossRef]

2) Trimble $\mathrm{MH}$, Brunt D, Jeon HS, et al.: Modulations of soleus H-reflex excitability during gait initiation: central versus peripheral influences. Muscle Nerve, 2001, 24: 1371-1379. [Medline] [CrossRef]

3) Breniere Y, Do MC: When and how does steady state gait movement induced from upright posture begin? J Biomech, 1986, 19: 1035-1040. [Medline] [CrossRef]

4) Brunt D, Lafferty MJ, Mckeon A, et al.: Invariant characteristics of gait initiation. Am J Phys Med Rehabil, 1991, 70: 206-212. [Medline] [CrossRef]

5) Crenna P, Frigo C: A motor programme for the initiation of forwardoriented movements in humans. J Physiol, 1991, 437: 635-653. [Medline] [CrossRef]

6) Rogers MW, Pai YC: Dynamic transitions in stance support accompanying leg flexion movements in man. Exp Brain Res, 1990, 81: 398-402. [Medline] [CrossRef]

7) Brunt $D$, Liu SM, Trimble M, et al.: Principles underlying the organization of movement initiation from quiet stance. Gait Posture, 1999, 10: 121-128. [Medline] [CrossRef]

8) Brunt D, Short M, Trimble M, et al.: Control strategies for initiation of human gait are influenced by accuracy constraints. Neurosci Lett, 2000, 285: 228-230. [Medline] [CrossRef]

9) Jian Y, Winter DA, Ischac MG, et al.: Trajectory of the body COG and COP during initiation and termination of gait. Gait Posture, 1993, 1: 9-22. [CrossRef]

10) Brenière $Y$, Cuong Do $M$, Bouisset $S$ : Are dynamic phenomena prior to stepping essential to walking? J Mot Behav, 1987, 19: 62-76. [Medline] [CrossRef]

11) Couillandre $A$, Brenière $Y$, Maton $B$ : Is human gait initiation program affected by a reduction of the postural basis? Neurosci Lett, 2000, 285: 150-154. [Medline] [CrossRef]

12) Ito $\mathrm{T}$, Azuma $\mathrm{T}$, Yamashita $\mathrm{N}$ : Anticipatory control in the initiation of a single step under biomechanical constraints in humans. Neurosci Lett, 2003, 352: 207-210. [Medline] [CrossRef]

13) Lepers $R$, Brenière $Y$, Maton $B$ : Changes to the gait initiation programme following a running exercise in human subjects. Neurosci Lett, 1999, 260: 69-73. [Medline] [CrossRef]

14) Cook T, Cozzens B: Human solutions for locomotion: III. The initiation of gait. In: Herman RM, Grillner S, Stein RB, Pearson KG, Smith RS, Redford JB, editors. Control of posture and gait. New York: Plenum Press, 1976, pp 65-76.

15) Gélat $T$, Pellec AL, Brenière Y: Evidence for a common process in gait initiation and stepping on to a new level to reach gait velocity. Exp Brain Res, 2006, 170: 336-344. [Medline] [CrossRef]

16) Brunt D, Santos V, Kim HD, et al.: Initiation of movement from quiet stance: comparison of gait and stepping in elderly subjects of different levels of functional ability. Gait Posture, 2005, 21: 297-302. [Medline] [CrossRef]

17) Kim HD: Effects of a dual-task on crossing an obstacle versus initiating gait. J Phys Ther Sci, 2008, 20: 249-253. [CrossRef]

18) Kim HD: Age-related changes in the center of pressure trajectory during obstacle crossing. J Phys Ther Sci, 2009, 21: 75-80. [CrossRef]

19) Kim HD: The effect of a dual-task on the center of pressure trajectory of 
healthy young adults during obstacle crossing. J Phys Ther Sci, 2009, 21 99-104. [CrossRef]

20) Kim HD: The influence of aging on the center of pressure trajectory: comparison of crossing an obstacle and stepping onto a curb from a position of quiet stance. J Phys Ther Sci, 2009, 21: 183-188. [CrossRef]

21) Kim HD, Je HD, Jeong JH, et al.: Effects of Tai Chi training on obstacle avoidance and gait initiation in older people. J Phys Ther Sci, 2013, 25 193-198. [CrossRef]

22) Couillandre A, Brenière Y: How does the heel-off posture modify gait initiation parameter programming? J Mot Behav, 2003, 35: 221-227. [Medline] [CrossRef]

23) Gélat $T$, Brenière $Y$ : Adaptation of the gait initiation process for stepping on to a new level using a single step. Exp Brain Res, 2000, 133: 538-546. [Medline] [CrossRef]

24) Hass CJ, Gregor RJ, Waddell DE, et al.: The influence of Tai Chi training on the center of pressure trajectory during gait initiation in older adults. Arch Phys Med Rehabil, 2004, 85: 1593-1598. [Medline] [CrossRef]

25) Ledebt A, Bril B, Brenière Y: The build-up of anticipatory behaviour. An analysis of the development of gait initiation in children. Exp Brain Res, 1998, 120: 9-17. [Medline] [CrossRef]

26) Michel V, Do MC: Are stance ankle plantar flexor muscles necessary to generate propulsive force during human gait initiation? Neurosci Lett 2002, 325: 139-143. [Medline] [CrossRef]

27) Sasaki O, Asawa $S$, Katsuno $S$, et al.: Gait initiation in bilateral vestibular loss. Auris Nasus Larynx, 2001, 28: 295-299. [Medline] [CrossRef]

28) Bensoussan L, Mesure S, Viton JM, et al.: Kinematic and kinetic asymmetries in hemiplegic patients' gait initiation patterns. J Rehabil Med, 2006 38: 287-294. [Medline] [CrossRef]

29) Dibble LE, Nicholson DE, Shultz B, et al.: Sensory cueing effects on maximal speed gait initiation in persons with Parkinson's disease and healthy elders. Gait Posture, 2004, 19: 215-225. [Medline] [CrossRef]

30) Hesse S, Reiter F, Jahnke M, et al.: Asymmetry of gait initiation in hemiparetic stroke subjects. Arch Phys Med Rehabil, 1997, 78: 719-724. [Medline] [CrossRef]

31) Martin M, Shinberg M, Kuchibhatla M, et al.: Gait initiation in community-dwelling adults with Parkinson disease: comparison with older and younger adults without the disease. Phys Ther, 2002, 82: 566-577. [Medline]

32) Mille ML, Johnson Hilliard M, Martinez KM, et al.: Acute effects of a lateral postural assist on voluntary step initiation in patients with Parkinson's disease. Mov Disord, 2007, 22: 20-27. [Medline] [CrossRef]

33) Patchay S, Gahery Y, Serratrice G: Gait initiation and impairments of ground reaction forces as illustrated in old age by 'La marche à petits pas' Neurosci Lett, 1997, 236: 143-146. [Medline] [CrossRef]

34) Timmann D, Horak FB: Perturbed step initiation in cerebellar subjects: 2 .
Modification of anticipatory postural adjustments. Exp Brain Res, 2001, 141: 110-120. [Medline] [CrossRef]

35) Tokuno CD, Eng JJ: Gait initiation is dependent on the function of the paretic trailing limb in individuals with stroke. Gait Posture, 2006, 24: 424-428. [Medline] [CrossRef]

36) Tokuno CD, Sanderson DJ, Inglis JT, et al.: Postural and movement adaptations by individuals with a unilateral below-knee amputation during gait initiation. Gait Posture, 2003, 18: 158-169. [Medline] [CrossRef]

37) Viton JM, Timsit M, Mesure S, et al.: Asymmetry of gait initiation in patients with unilateral knee arthritis. Arch Phys Med Rehabil, 2000, 81: 194-200. [Medline] [CrossRef]

38) Bohannon RW, Andrews AW, Smith MB: Rehabilitation goals of patients with hemiplegia. Int J Rehabil Res, 1988, 11: 181-184. [CrossRef]

39) Bohannon RW, Horton MG, Wikholm JB: Importance of four variables of walking to patients with stroke. Int J Rehabil Res, 1991, 14: 246-250. [Medline] [CrossRef]

40) Hsu AL, Tang PF, Jan MH: Analysis of impairments influencing gait velocity and asymmetry of hemiplegic patients after mild to moderate stroke. Arch Phys Med Rehabil, 2003, 84: 1185-1193. [Medline] [CrossRef]

41) Lin PY, Yang YR, Cheng SJ, et al.: The relation between ankle impairments and gait velocity and symmetry in people with stroke. Arch Phys Med Rehabil, 2006, 87: 562-568. [Medline] [CrossRef]

42) Hägg GM, Luttmann A, Jäger M: Methodologies for evaluating electromyographic field data in ergonomics. J Electromyogr Kinesiol, 2000, 10: 301-312. [Medline] [CrossRef]

43) Fitts PM: The information capacity of the human motor system in controlling the amplitude of movement. J Exp Psychol, 1954, 47: 381-391. [Medline] [CrossRef]

44) Fitts PM, Peterson JR: Information capacity of discrete motor responses. J Exp Psychol, 1964, 67: 103-112. [Medline] [CrossRef]

45) Freund HJ, Büdingen HJ: The relationship between speed and amplitude of the fastest voluntary contractions of human arm muscles. Exp Brain Res, 1978, 31: 1-12. [Medline] [CrossRef]

46) Monohar VJ, Brunt D, Robichaud JA: Limits of the dual-strategy hypothesis in an isometric plantar flexion contraction. Exp Brain Res, 1998, 122: 459-466. [Medline] [CrossRef]

47) Brenière Y, Do MC: Control of gait initiation. J Mot Behav, 1991, 23: 235 240. [Medline] [CrossRef]

48) Lepers R, Brenière $Y$ : The role of anticipatory postural adjustments and gravity in gait initiation. Exp Brain Res, 1995, 107: 118-124. [Medline] [CrossRef]

49) Jones SF, Twigg PC, Scally AJ, et al.: The gait initiation process in unilateral lower-limb amputees when stepping up and stepping down to a new level. Clin Biomech (Bristol, Avon), 2005, 20: 405-413. [Medline] [CrossRef] 